\title{
RENEWAL MANAGEMENT FRAMEWORK FOR URBAN RAIL TRANSIT ASSETS
}

\author{
Wenfei BAI ${ }^{1,2}$, Rengkui $\mathrm{LIU}^{3}, \mathrm{Ru} \mathrm{AN}^{4}$, Futian $\mathrm{WANG}^{5}$, Quanxin $\mathrm{SUN}^{6}$ \\ 1,3-5 State Key Laboratory of Rail Traffic Control and Safety, Beijing Jiaotong University, China \\ ${ }^{2}$ National Engineering Laboratory for Green and Safe Construction Technology in Urban Rail Transit, \\ Beijing Urban Construction Design and Development Group Co Ltd, China \\ ${ }^{6}$ MOE Key Laboratory for Urban Transportation Complex Systems Theory and Technology, \\ Beijing Jiaotong University, China
}

Received 28 September 2017; revised 11 December 2017; accepted 25 April 2018

\begin{abstract}
Decision-making surrounding asset renewal is essential for the efficient use of renewal resources and safe operation of urban rail transit. In this study, major problems in the current management of urban rail industries in countries with the same problems as those in China were analysed, and in response, a renewal management framework based on service life estimation was proposed to provide adequate decision-making support for urban rail transit assets. In this framework, the cumulative failure frequency of an asset is used to indicate its health condition, and considering the uncertainties and heterogeneities in the deterioration process of assets, a Poisson-Weibull process model-based methodology was developed to estimate the service and residual lives of each asset, which are then employed in analysing its renewal demand and renewal period. Finally, the model is validated through an empirical study of rail renewal in the Beijing Metro. Our evaluation demonstrates that the proposed framework can estimate each asset's service life accurately and can be used by asset management personnel to establish reasonable renewal plans and provide decision-making support for a scientifically informed resource allocation, thus mitigating major problems in current management practices.
\end{abstract}

Keywords: urban rail transit, China, asset renewal, Poisson-Weibull process, service life, residual life.

\section{Introduction}

Urban rail transit is one of the most effective ways of meeting the public's travel needs and alleviating urban traffic congestion, and governments in many countries and regions have made significant investments to develop it. In many cities, such as London, Paris, New York, and Tokyo, of developed countries, urban rail transit has been operating for many years. Further, in many cities of developing countries, it has been developing rapidly. For example, 30 cities in mainland China were successfully served by urban rail transit on main lines in 2016, with a total of 133 lines and $4152.8 \mathrm{~km}$ of operations mileage (CAM 2017). To modernise the inventory and sustain safety and operability, the assets of urban rail transit require continuous renewal (Rashedi, Hegazy 2015). However, progressively expanding assets and continuously increasing working hours not only quickly increase renewal costs, creating acute financial pressure for the local government (Zhang, Han 2011), but also pose a tough challenge for asset man- agers to optimally allot limited renewal resources (Chen, $\mathrm{Ng}$ 2007). Therefore, determining appropriate renewal actions is of great significance in ensuring safe operation while effectively controlling asset management expenses.

\section{Background}

\subsection{Asset renewal management in urban rail industries}

In many countries, such as China, design working life and health condition are the 2 major bases of managing asset renewal in urban rail industries (Scarf et al. 2007; Scarf, Hartman 2008; DB 11/T718:2016):

- Asset renewal management based on design working life. When an asset reaches the end of its design working life, it should be renewed; if instead it fails before reaching the end of its design working life, maintenance should be performed to sustain the asset's operability. The relevant design or management standards (IEC 62278:2002; GB 50490:2009;

*Corresponding author. E-mail: ftwang_bjtu@yeah.net 
GB 50157:2013; DB 11/995:2013; ISO 2394:2015; DB 11/T718:2016) and asset suppliers are the main source of design working life. However, the service processes of assets are influenced by many heterogeneous factors, resulting in the uncertainty and heterogeneity of deterioration processes of different assets (Durango-Cohen, Madanat 2008); thus, the actual service lives of assets may differ from their design lives, and the actual service lives of assets of the same type in diverse operating environments can vary. Asset renewal management based on the design working life ignores uncertainty and heterogeneity in deterioration. As such, resource waste may easily be caused by unnecessarily replacing an asset that has reached the end of its design life but can remain in service; conversely, hidden safety risks may result from failure to replace an asset that has not reached the end of its design life but cannot remain in service (Zhang, Han 2011);

- Asset renewal management based on health condition. When failures occur frequently in an asset before the end of its design working life, a manager should organise experts to evaluate whether the asset's health condition meets safety requirements by using its inspection and maintenance records, then make a qualitative renewal decision (DB 11/T718:2016). However, because of the scale of assets, this method is inefficient in operations requiring significant time and funds, and may add to the workload of asset managers and reduce management efficiency ( $\mathrm{Li}$, Wang 2012).

The aforementioned problems in asset renewal management for urban rail transit hinder asset managers' ability to renew assets scientifically and rationally, and may lead to wasted resources or potential danger.

\subsection{Literature review}

Many models have been developed to support infrastructural asset renewal decisions. Some researchers have proposed that asset renewal should be decided based on a condition, which is usually represented by discrete ratings or states. For example, Mishalani and Madanat (2002) divided concrete bridge deck condition into ten ratings, characterised its deterioration, and predicted its future condition state by using a time-based stochastic duration model to support renewal decision making. Zambon et al. (2017) also examined bridge decks and used stochastic prediction, including Markov chain, Markov process, and Gamma process models, to predict a bridge deck condition (as discretised into six ratings); these ratings determined whether the bridge deck needed to be renewed. Baik et al. (2006) modelled the deterioration of sewer pipe by using a Markov chain model in which the pipe condition was represented by five discrete states and the transition probabilities between the states were estimated using an ordered probit model-based methodology for developing appropriate proactive maintenance and renewal strategies.
Han et al. (2014) classified the highway pavement condition into five states by using three performance indicators: cracking, rutting, and the international roughness index. Pavement deterioration was characterised using a Markov hazard model and Bayesian estimation. Andrade and Teixeira (2013) presented a hierarchical Bayesian model to predict rail track geometry degradation, which was quantified in terms of longitudinal-level defects, and thus guided planning maintenance and renewal actions.

Researchers have optimised renewal decisions by considering not only asset condition but also management costs. Durango-Cohen and Madanat (2002) presented two optimisation models for maintenance and renewal decisions regarding infrastructure assets over a finite planning horizon. One model integrated the Markov decision process formulation and a Bayesian approach under uncertain asset deterioration rates, while the other integrated latent Markov decision process formulation and a quasiBayesian approach under performance model uncertainty (Durango-Cohen, Madanat 2008). Caetano and Teixeira $(2013,2016)$ proposed two multi-objective optimisation models based on the Non-Sorting Genetic Algorithm 2 (NSGA2) for planning railway ballast, rail, and sleeper renewal operations by separately considering the track Life Cycle Cost (LCC)-unavailability trade-off and LCCreliability trade-off. Rashedi, Hegazy $(2015,2016)$ and Hegazy, Rashedi (2013) used genetic algorithms, an advanced modelling tool (GAMS/CPLEX), and system dynamics to handle capital renewal optimisation problems for network-level infrastructure assets in terms of condition and LCC. Barone and Frangopol (2014) developed four bi-objective approaches to optimise the life-cycle maintenance and renewal plans of deteriorating structures by considering cost and four performance indicators: reliability, risk, availability, and hazard.

Other studies focused on estimating an asset's service life to determine its renewal period. Aoki et al. (2007) and Kobayashi et al. (2010) verified the efficacy of applying a Weibull distribution function to empirically estimate the service lives of tunnel reflectors, and using binary and multiple condition states to describe the deterioration process. In addition, Zakeri and Shahriari (2012) developed a time-based probabilistic discrete-state deterioration model by using a Weibull distribution to analyse the distribution of the duration over which a rail wear degrades to specified states. Kobayashi et al. (2012) proposed a deterioration forecasting model for highway pavement to estimate its service life and provide renewal decision-making support; this model expressed the deterioration speed in two or more condition states in conjunction with elapsed time and followed an exponential distribution function. Bai et al. (2015) presented an approach utilizing a Markov stochastic process to analyse the life expectancy of railway track irregularities, in which deterioration states were described through a track quality index and discretised into four ranks, and deterioration processes were characterised using an exponential hazard model. 


\subsection{Objectives of current paper}

Although numerous studies have examined asset renewal, it is still not well managed in the urban rail industries of many countries, such as China (Liu et al. 2011). In response to the existing problems pointed out earlier, this paper proposes a renewal management framework based on service life estimation to provide decision-making support for the assets of urban rail transit. In the proposed framework, the cumulative failure frequency of an asset is selected as its health condition indicator. Furthermore, considering the uncertainties and heterogeneities in the deterioration process of assets, a Poisson-Weibull process model-based methodology was developed to estimate the service and residual lives of each asset for analysing its renewal demand and renewal period based on its inspection records.

\section{Research methodology}

\subsection{Model framework}

Figure 1 shows the proposed renewal management framework based on service life estimation. Compared with existing management methods analysed in Section 1.1, the proposed model provides several improvements:

- each single asset is regarded as a unit, the renewal demand and period of which are analysed individually, considering the uncertainty and heterogeneity in deterioration;

- asset health, as evaluated by cumulative failure frequency, is selected as the basis of asset renewal, considering the actual operating condition;

- a Poisson-Weibull process model-based methodology is developed to estimate the service life of each asset, which can then be used to analyse the renewal demand and renewal period quantitatively, and guide planning appropriate renewal action.

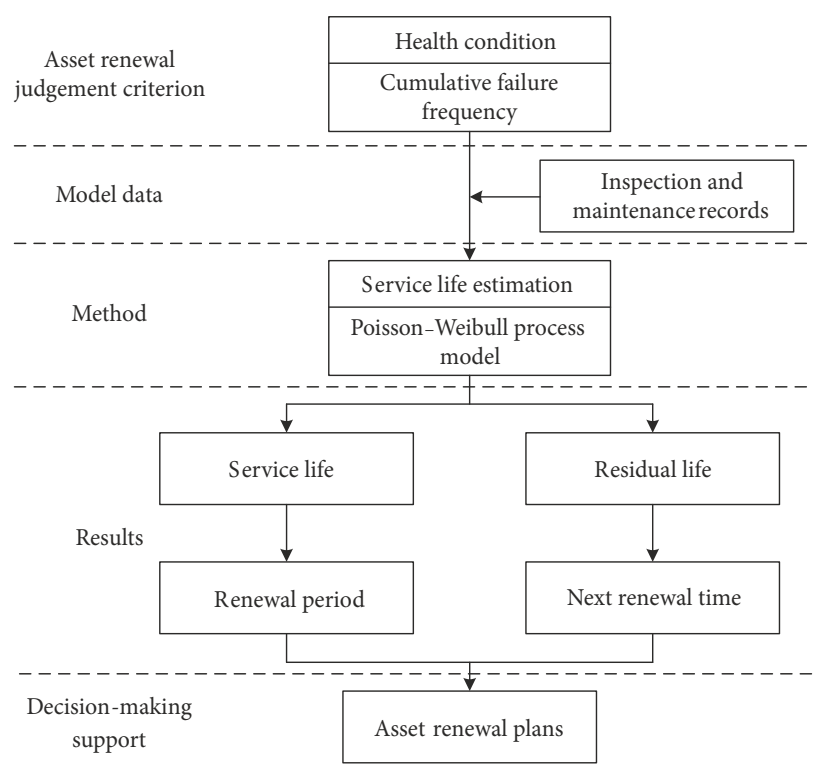

Figure 1. Proposed renewal management framework for urban rail transit assets

\subsection{Model for estimating service life}

Given that infrastructure assets deteriorate naturally with time and the occurrence of various failures in their service lives (Mishalani, Gong 2009), in this study, the cumulative failure frequency of an asset was selected to reflect its health condition; an asset should be renewed when $N$ failures have occurred. Among the diverse types of assets, the thresholds for $N$ are inconsistent, and these values should be based on individual management requirements.

For asset $k(k=1,2, \ldots, K), T_{0}^{k}$ represents the initial time at which it is put into use, and $T_{1}^{k}, T_{2}^{k}, T_{3}^{k}, \ldots, T_{N}^{k}$ represents its $N(N \geq 1)$ failures. Hence, time interval $X_{i}^{k}$ between two successive failures can be expressed as:

$$
X_{i}^{k}=T_{i}^{k}-T_{i-1}^{k}, i=1,2,3, \ldots, N,
$$

where: $N^{k}(t)$ represents the cumulative failure frequency of interval $(0, t]$; thus, $N^{k}(0)=0$. In general, cumulative failure frequencies of two disjoint intervals are independent (Cao, Cheng 2012). As a result of this stipulation, the authors assume that $N^{k}(t)$ has independent increments, that is, $N^{k}\left(b_{i}\right)-N^{k}\left(a_{i}\right)$ of disjoint intervals $\left(a_{i}, b_{i}\right]$, $(i=1,2, \ldots, n)$ with arbitrary $n$ are independent. For any $0 \leq t<s$, the cumulative failure frequency $i$ of interval $(t, s]$ corresponds to a Poisson distribution with parameter $\Lambda(t, s)$, and can be expressed as:

$$
\begin{aligned}
& P\left(N^{k}(s)-N^{k}(t)=i\right)= \\
& \frac{\left(\Lambda^{k}(t, s)\right)^{i}}{i !} \cdot \exp \left(-\Lambda^{k}(t, s)\right),
\end{aligned}
$$

where: $\Lambda^{k}(t, s)$ is given by the following equation:

$$
\Lambda^{k}(t, s)=\int_{t}^{s}\left(\varphi^{k}(\mu)\right) d \mu,
$$

in which $\varphi^{k}(t)$ is a non-negative function representing the hazard rate of asset $k$ at time $t$. A Weibull hazard rate function is used to represent $\varphi^{k}(t)$ through the following equation:

$$
\varphi^{k}(t)=\lambda^{k} \cdot \beta^{k} \cdot t^{\beta^{k}-1}, t \geq 0, \lambda^{k}, \beta^{k}>0 .
$$

\subsubsection{Calculation of service life}

The probability distribution density function for the service life of asset $k$ can be expressed as:

$$
\begin{aligned}
& f^{k}(x)=\frac{\left(\int_{0}^{x}\left(\lambda^{k} \cdot \beta^{k} \cdot u^{\beta^{k}-1}\right) d \mu\right)^{N-1}}{(N-1) !} \lambda^{k} \cdot \beta^{k} \cdot x^{\beta^{k}-1} \times \\
& \exp \left(-\int_{0}^{x}\left(\lambda^{k} \cdot \beta^{k} \cdot u^{\beta^{k}-1}\right) d \mu\right),
\end{aligned}
$$

where: $x$ is the service life of asset $k$. The service life $A L^{k}(x)$ is then expressed by:

$$
A L^{k}(x)=\int_{0}^{\infty}\left(x \cdot f^{k}(x)\right) d x .
$$

An asset's renewal period can be determined based on its service life. 


\subsubsection{Calculation of residual life}

By assuming $j(0 \leq j<N)$ failures occurred prior to time $t$, i.e., $N^{k}(t)=j$, the probability distribution density function for the residual service life of asset $k$ can be expressed as:

$$
\begin{gathered}
f^{k}(s)=\frac{\left(\int_{t}^{t+s}\left(\lambda^{k} \cdot \beta^{k} \cdot u^{\beta^{k}-1}\right) d \mu\right)^{N-j-1}}{(N-j-1) !} \times \\
\lambda^{k} \cdot \beta^{k}(t+s)^{\beta^{k}-1} \cdot \exp \left(-\int_{t}^{t+s}\left(\lambda^{k} \cdot \beta^{k} \cdot u^{\beta^{k}-1}\right) d \mu\right),
\end{gathered}
$$

where: $s$ is the residual service life of asset $k$. The expected residual life $R L^{k}(s)$ is then expressed by:

$$
R L^{k}(s)=\int_{0}^{\infty}\left(s \cdot f^{k}(s)\right) d s .
$$

Based on the residual life calculation, the next period at which the asset should be renewed can be determined.

\subsubsection{Parameter estimation}

Parameters $\lambda^{k}$ and $\beta^{k}$ in Equations (4)-(8) must be estimated and are variable between different assets owing to the uncertainties and heterogeneities in their deterioration process. These values can be determined using maximum likelihood estimation based on each asset's historical inspection data. If $n$ failures occurred between the initial time and time $t, 0 \leq T_{1}^{k} \leq \cdots \leq T_{n}^{k} \leq t$, then the joint probability density of $T_{1}^{k}, \ldots, T_{n}^{k}$ can be written as:

$$
\begin{aligned}
& f\left(T_{1}^{k}, \ldots, T_{n}^{k}\right)=\exp \left(-\int_{0}^{T_{n}^{k}}\left(\lambda^{k} \cdot \beta^{k}\left(T_{n}^{k}\right)^{\beta^{k}-1}\right) d \mu\right) \times \\
& \prod_{i=1}^{n}\left(\lambda^{k} \cdot \beta^{k}\left(T_{i}^{k}\right)^{\beta^{k}-1}\right) .
\end{aligned}
$$

The values of parameters $\lambda^{k}$ and $\beta^{k}$ can be obtained from $\frac{\partial f\left(T_{1}^{k}, \ldots, T_{n}^{k}\right)}{\partial \lambda^{k}}=0$ and $\frac{\partial f\left(T_{1}^{k}, \ldots, T_{n}^{k}\right)}{\partial \beta^{k}}=0$ expressed by Equations (10) and (11), respectively:

$$
\begin{aligned}
& \hat{\beta}^{k}=\frac{n}{\sum_{i=1}^{n} \ln \frac{t}{T_{i}^{k}}} ; \\
& \hat{\lambda}^{k}=\frac{n}{t^{\hat{\beta}^{k}}} .
\end{aligned}
$$

\section{Empirical analysis}

Rail is an important urban rail transit asset. Hence, an empirical analysis of rail renewal in the Beijing Metro was used to verify the proposed method's applicability.

\subsection{Overview}

In China, rail transit management departments generally refer to the replacement of rail segments longer and shorter than $1000 \mathrm{~m}$ as renewal and maintenance, respectively (DB 11/T718:2016). To reduce the impact of uncertainty and heterogeneity in rail deterioration, continuous rails on a line of track are divided into segments of $1000 \mathrm{~m}$; each segment is regarded as an individual asset for analysis of renewal demand and renewal period. A schematic of the division of rail segments is shown in Figure 2.

The health condition of a rail is most often indicated by the state of rail defects (such as shelling, fatigue cracks, oval flaws, and wear). In China, rail defect evolution is divided into the following four ranks: small, aggravated, severe, and broken rail defects (The Railway Ministry... 2010) based on wear volumes or fatigue defects. The Beijing Metro track maintenance rules $(\mathrm{QB}(\mathrm{J}) / \mathrm{BDY}(\mathrm{A}) \mathrm{XL}$ 003:2009) stipulate that severely defective and broken rails must be replaced in a timely manner. The rules of railway track maintenance (The Railway Ministry... 2010) state that rail renewal should be scheduled when the concentration of average cumulative severe and broken rail defects is $2 \ldots 4$ defects per kilometre.

As a result of the above stipulation, severe and broken rail defects were regarded as failures in this study, and the health condition of a rail segment was quantified by the number of cumulative severe and broken rail defects. In the Beijing Metro, if the number of cumulative severe and broken rail defects in a rail segment is equal to or greater than three, the rail segment must be renewed, i.e., all rails along that segment must be replaced. The standards for severe rail defects in the Beijing Metro are shown in Tables 1 and 2, and the standards for broken rail defects are shown in Table 3 (QB(J)/BDY(A)XL 003:2009).

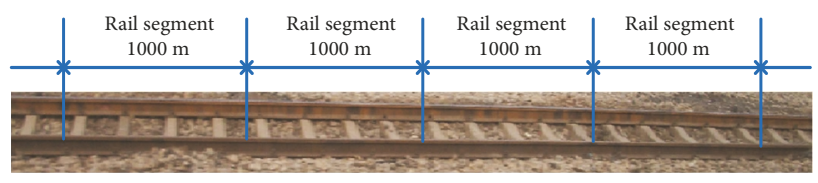

Figure 2. Schematic of the division of rail segments

Table 1. Standards for severe rail defects in the Beijing Metro

\begin{tabular}{|l|l|}
\hline \multicolumn{1}{|c|}{ Indicators } & \multicolumn{1}{c|}{ Physical description } \\
\hline Surface crack & surface cracks include bolt hole cracks, head longitudinal cracks, base cracks, etc. \\
\hline Subsurface crack & subsurface cracks include over flaws, longitudinal vertical cracks, transverse cracks, etc. \\
\hline Shelling & length $\geq 30 \mathrm{~mm}$ and depth $\geq 8 \mathrm{~mm}$ \\
\hline Deformation & rail deformation includes plastic flow, tongue lipping, etc. \\
\hline Rail end batter & $\geq 5 \mathrm{~mm}$ \\
\hline Corrosion & depth of edge of rail base $\leq 5 \mathrm{~mm}$ or depth of rail web $\leq 8 \mathrm{~mm}$ after cleaning \\
\hline Rail wear & above the standard shown in Table 3 \\
\hline
\end{tabular}


Table 2. Standards for severe rail wear defects in the Beijing Metro

\begin{tabular}{|c|c|c|}
\hline Type of rail $[\mathrm{kg} / \mathrm{m}]$ & Vertical wear $[\mathrm{mm}]$ & Side wear $[\mathrm{mm}]$ \\
\hline 60 & 10 & 17 \\
\hline 50 & 9 & 15 \\
\hline 43 & 8 & 13 \\
\hline
\end{tabular}

Table 3. Standards for broken rail defects in the Beijing Metro

\begin{tabular}{|l|l|}
\hline \multicolumn{1}{|c|}{ Indicators } & \multicolumn{1}{c|}{ Physical description } \\
\hline Cross-section & the cross-section has broken into two parts \\
\hline Head crack & $\begin{array}{l}\text { a crack has cut across the rail-head } \\
\text { cross-section }\end{array}$ \\
\hline Base crack & $\begin{array}{l}\text { a crack has cut across the rail-base } \\
\text { cross-section }\end{array}$ \\
\hline Shelling & length $\geq 50 \mathrm{~mm}$ and depth $\geq 10 \mathrm{~mm}$ \\
\hline
\end{tabular}

\subsection{Estimated service life}

In this empirical analysis, 96 rail segments across four lines (Lines 1, 2, 10, and Yizhuang) in the Beijing Metro, in which severe or broken rail defects had occurred, were considered, as shown in Table 4.
Table 4. The 96 rail segments considered, from four lines of the Beijing Metro

\begin{tabular}{|c|c|c|c|c|}
\hline Line & $\begin{array}{c}\text { Type of } \\
\text { rail }[\mathrm{kg}]\end{array}$ & $\begin{array}{c}\text { Type of } \\
\text { track }\end{array}$ & $\begin{array}{c}\text { Average annual } \\
\text { gross tonnage } \\
\text { [Million Gross } \\
\text { Tonnes (MGT)] }\end{array}$ & $\begin{array}{c}\text { Number } \\
\text { of rail } \\
\text { segments }\end{array}$ \\
\hline Line 1 & 50 & jointless & 38.14 & 15 \\
\hline Line 2 & 50 & jointed & 35.41 & 39 \\
\hline Line 10 & 60 & jointless & 36.54 & 25 \\
\hline $\begin{array}{c}\text { Line } \\
\text { Yizhuang }\end{array}$ & 60 & jointless & 29.76 & 17 \\
\hline
\end{tabular}

Based on the rail defect inspection data of these rail segments from January 2008 to March 2017, the values of $\lambda^{k}$ and $\beta^{k}$ for each rail segment were calculated using maximum likelihood estimation. Moreover, based on these estimated values, the service and residual lives of these rail segments were determined using the proposed method, as illustrated in Figures 3 and 4, respectively.

As shown in Figures 3 and 4, for the results calculated from the proposed method, both the service and residual lives for different rail segments are heterogeneous, which is consistent with the actual rail degradation. The deterioration of a rail segment is influenced by many factors, including spatial location factors (such as curves,

a)

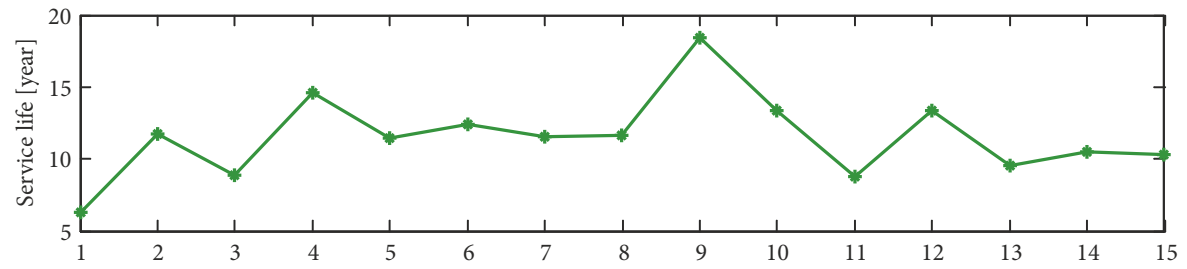

b)

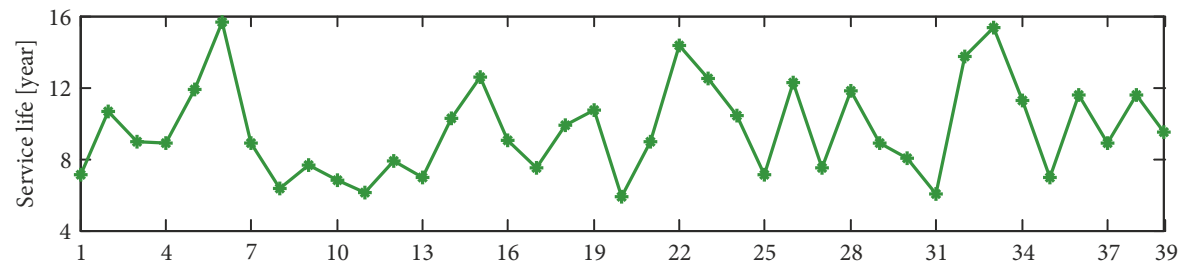

c)

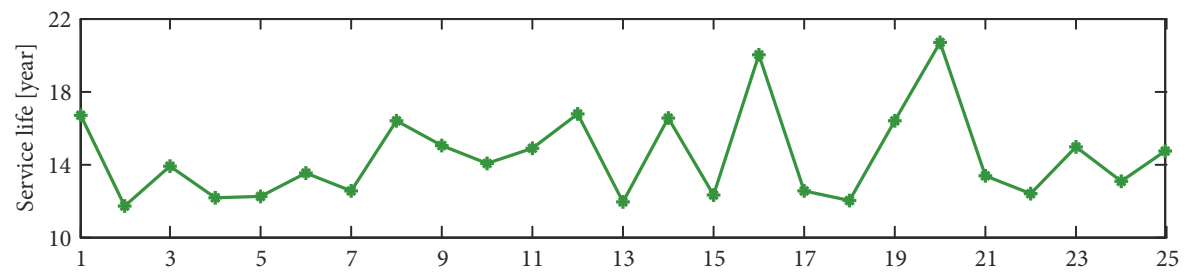

d)

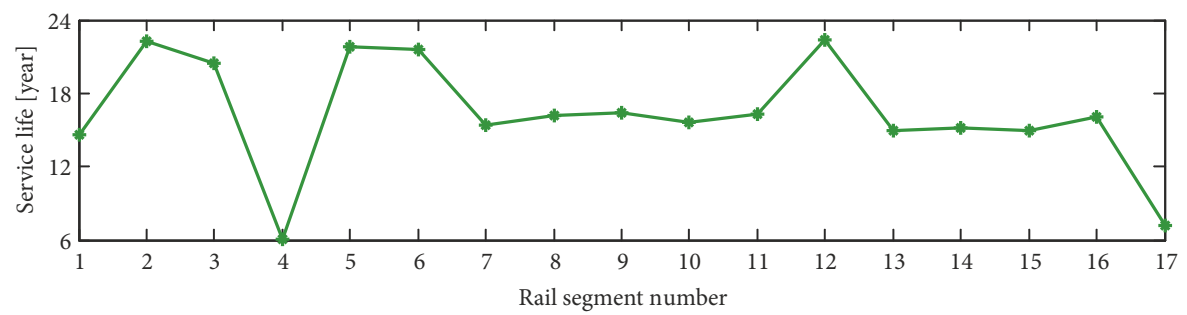

Figure 3. Estimated service lives of rail segments: a - rail segments of Line 1; b - rail segments of Line 2; $\mathrm{c}$ - rail segments of Line 10; $\mathrm{d}$ - rail segments of Line Yizhuang 
a)

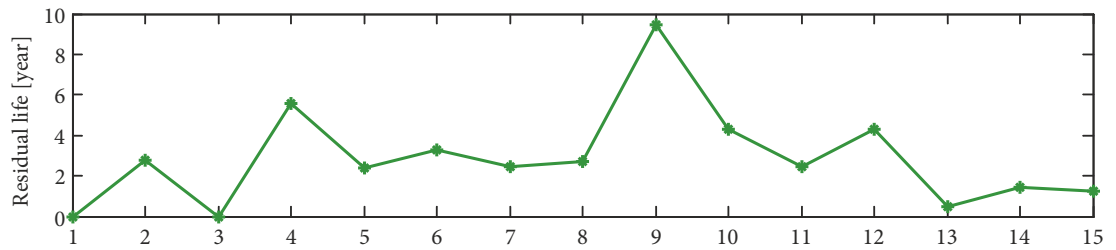

b)

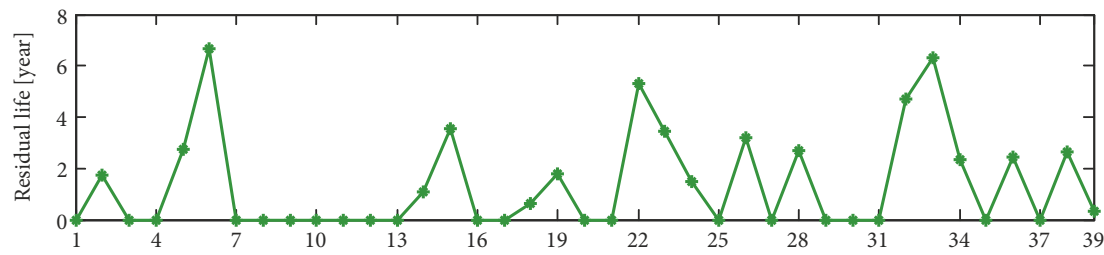

c)

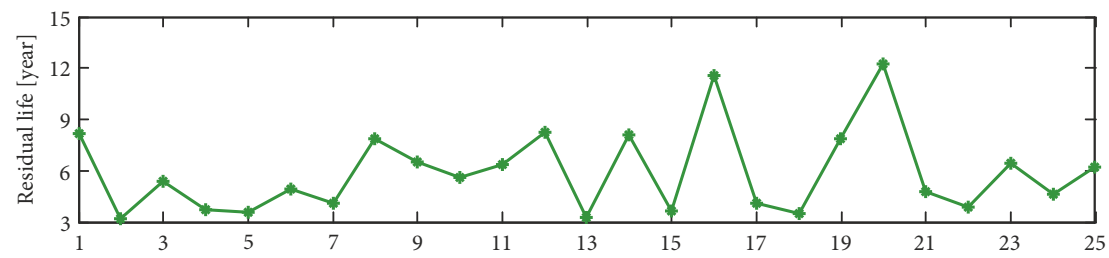

d)

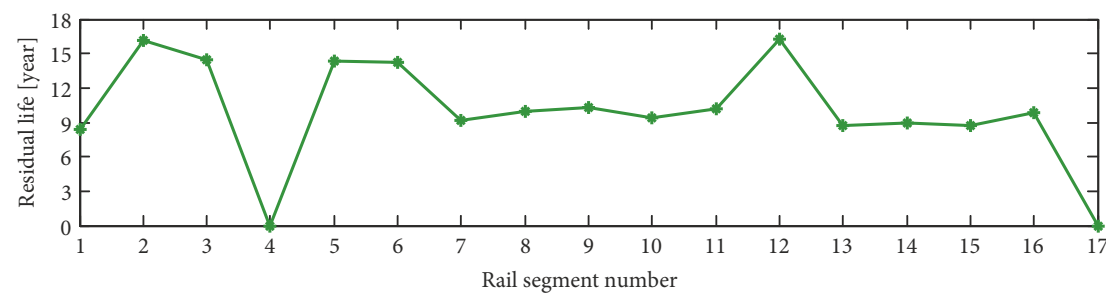

Figure 4. Estimated residual lives of rail segments: a - rail segments of Line 1; b - rail segments of Line 2; $\mathrm{c}$ - rail segments of Line 10; $\mathrm{d}$ - rail segments of Line Yizhuang

a)

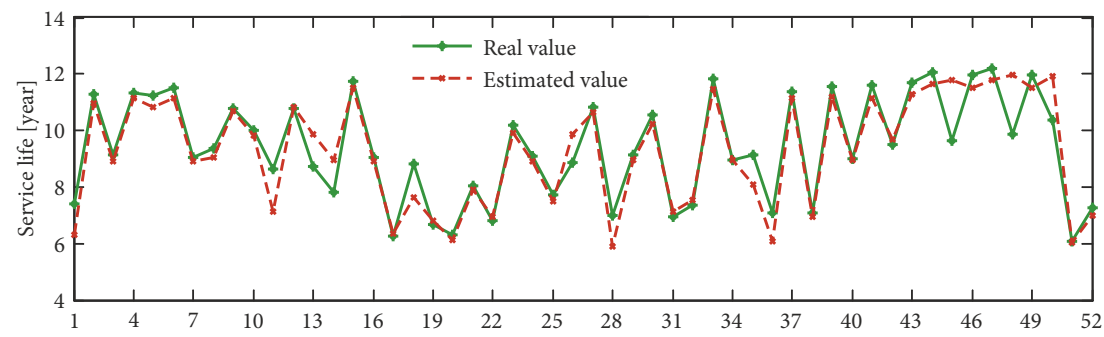

b)

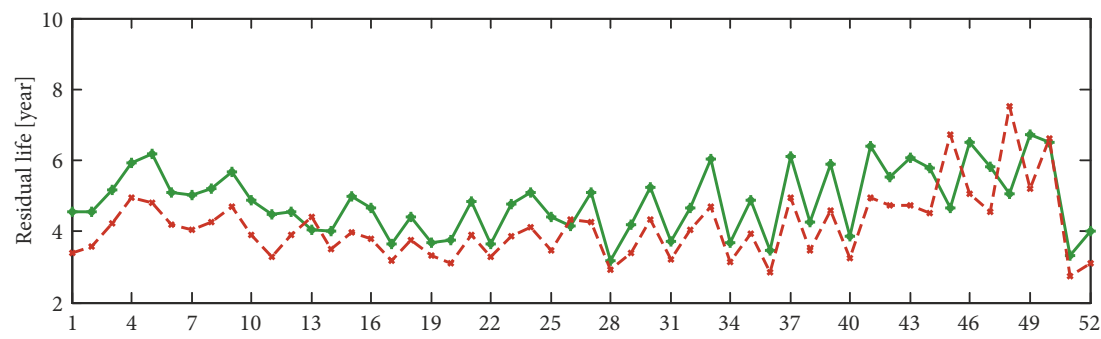

c)

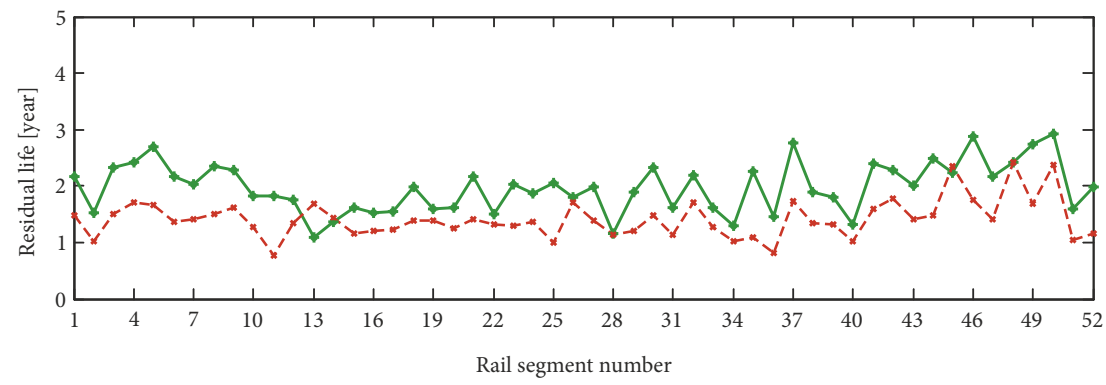

Figure 5. Comparison of estimated and true values of the service and residual lifetimes of the 52 selected rail segments: $\mathrm{a}$ - service life; $\mathrm{b}$ - residual life when one severe or broken rail defect occurred;

$c$ - residual life when two severe or broken rail defects occurred 
grades, and bridge-subgrade/tunnel-subgrade transitions), transportation factors (such as the type of rolling stock, cumulative gross tonnage, and train traffic speed/ weight), design factors (such as the rail material and type or track bed type), track-associated facility factors (such as track regularity, curve smoothness, and ballast condition), maintenance factors (such as maintenance period and activities), and natural factors (such as temperature and humidity). The deterioration of different rail segments in separate locations is affected by different heterogeneous factors occurring at different rates over different rail renewal periods (Bai et al. 2015). The proposed method accounts for the uncertainty and heterogeneity in asset deterioration. Compared with the actual track maps, the rail segments, for which the service lives are relatively short, are mostly located on sharp curves and their deterioration rates are faster under the influence of rail wear.

\subsection{Estimation error analysis}

To evaluate the accuracy of the proposed model, 52 rail segments, in which severe or broken rail defects occurred more than three times, were selected from the 96 rail segments. Moreover, the estimated values of their service and residual lifetimes at each occurrence of a severe or broken rail defect (the first two times) were compared with the actual values, as illustrated in Figure 5. In this study, the actual service life for each rail segment is the time span from the date when the rail is put into use to the date when three severe or broken rail defects occurred.

Table 5 lists the comparison of the average estimated and actual values for the service and residual lifetimes of the 52 selected rail segments.

The results in Figure 5 show that the variation tendencies of the estimated values for different rail segments for, both the service and residual lives are consistent with the actual values and most of the estimated values are less than the actual values. In addition, as shown in Table 5, the average estimated value is less than the average actual value. This indicates that the results estimated using the proposed model can assist asset managers in developing rail renewal plans in advance, allowing them to address potential safety risks in the railroad before development.

To further analyse the error of the estimation results, the estimation errors of service life $\varepsilon_{s}$, residual life when one severe or broken rail defect occurs $\varepsilon_{r}^{1}$, and residual life when two severe or broken rail defects occurred $\varepsilon_{r}^{2}$ were analysed. The results are illustrated in Figure 6 and Table 6.

The results given in Table 6 indicate the following:

- for $\varepsilon_{s}$, the average and median results are -0.11 and -0.20 years, respectively, and the first and third quartile results are -0.39 and 0.03 years, respectively; further, $76.92 \%$ of $\left|\varepsilon_{s}\right|$ were less than a year;

- for $\varepsilon_{r}^{1}$, the average and median results are -0.72 and -0.91 years, respectively, and the first and third quartile results are -0.98 and 0.58 years, respectively; in addition, $73.08 \%$ of $\left|\varepsilon_{r}^{1}\right|$ are less than a year;
Table 5. Comparison of the average estimated and actual values of 52 selected rail segments

\begin{tabular}{|l|c|c|}
\hline \multicolumn{1}{|c|}{ Item } & $\begin{array}{c}\text { Average } \\
\text { estimated } \\
\text { value [year] }\end{array}$ & $\begin{array}{c}\text { Average } \\
\text { actual value } \\
\text { [year] }\end{array}$ \\
\hline Service life & 9.29 & 9.40 \\
\hline $\begin{array}{l}\text { Residual life when one severe } \\
\text { or broken rail defect occurred }\end{array}$ & 4.13 & 4.85 \\
\hline $\begin{array}{l}\text { Residual life when two severe } \\
\text { or broken rail defects occurred }\end{array}$ & 1.42 & 1.98 \\
\hline
\end{tabular}

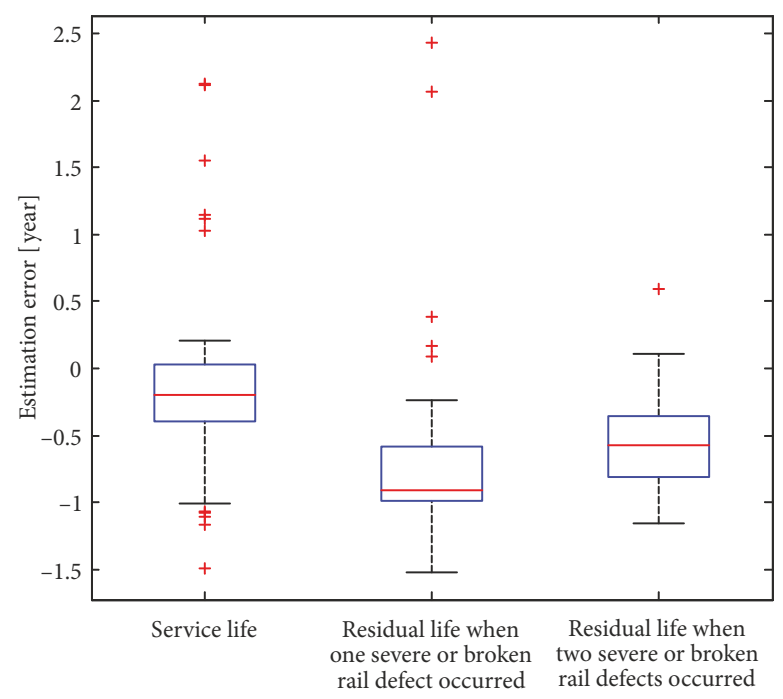

Figure 6. Box plot of estimation errors for service and residual lives

Table 6. Distributions of estimation errors

\begin{tabular}{|l|c|c|c|}
\hline \multirow{2}{*}{ Item } & $\begin{array}{c}\text { Absolute value } \\
\text { of estimation } \\
\text { error } \varepsilon \text { [year] }\end{array}$ & $\begin{array}{c}\text { Number of } \\
\text { rail segments }\end{array}$ & $\begin{array}{c}\text { Percentage } \\
\text { [\%] }\end{array}$ \\
\hline Service life & $\left|\varepsilon_{s}\right| \leq 1$ & 40 & 76.92 \\
\cline { 2 - 4 } & $1<\left|\varepsilon_{s}\right| \leq 2$ & 10 & 19.23 \\
\cline { 2 - 4 } & $\left|\varepsilon_{s}\right|>2$ & 2 & 3.85 \\
\hline $\begin{array}{l}\text { Residual service } \\
\text { life when one } \\
\text { severe or broken } \\
\text { rail defect } \\
\text { occurred }\end{array}$ & $\left|\varepsilon_{r}^{1}\right| \leq 1$ & 38 & 73.08 \\
\cline { 2 - 4 } & $1<\left|\varepsilon_{r}^{1}\right| \leq 2$ & 12 & 23.07 \\
\cline { 2 - 4 } $\begin{array}{l}\text { Residual service } \\
\text { life when two } \\
\text { severe or broken } \\
\text { rail defects } \\
\text { occurred }\end{array}$ & $\left|\varepsilon_{r}^{1}\right|>2$ & 2 & 3.85 \\
\cline { 2 - 4 } & $|<| \varepsilon_{r}^{2} \mid \leq 1$ & 44 & 84.62 \\
\cline { 2 - 4 } & $\left|\varepsilon_{r}^{2}\right|>2$ & 8 & 15.38 \\
\hline
\end{tabular}

- for $\varepsilon_{r}^{2}$, the average and median results are -0.56 and -0.57 years, respectively, and the first and third quartile results are -0.80 and -0.37 years, respectively; in addition, $84.62 \%$ of $\left|\varepsilon_{r}^{2}\right|$ are less than a year. 
Considering that the Beijing Metro track maintenance rules $(\mathrm{QB}(\mathrm{J}) / \mathrm{BDY}(\mathrm{A}) \mathrm{XL}$ 003:2009) require that rail renewal plans should be established $1 . . .2$ years in advance, the accuracy of the model proposed in this paper would allow management personnel to compose a reasonable renewal plan, providing sufficiently accurate estimation of the residual service life to support renewal decisions and a quantifiable, scientific basis for the allocation of resources.

\subsection{Comparison with the existing renewal method}

According to the current Beijing Metro track maintenance rules $(\mathrm{QB}(\mathrm{J}) / \mathrm{BDY}(\mathrm{A}) \mathrm{XL}$ 003:2009), the basis of rail renewal is its design working life, i.e., the accumulated gross tonnage, which is presented in Table 7. A comparison between the estimated service life values for the 52 selected rail segments obtained using the proposed method and accumulated gross tonnage and the actual values is shown in Figure 7.

The results presented in Figure 7 show the following:

- unlike the proposed method, the results calculated through the accumulated gross tonnage are consistent for rail segments on the same line and are heterogeneous for rail segments on different lines because of the similar accumulated gross tonnage of the rails on a given line; the determination of the service lives of rail segments through the accumulated gross tonnage disregards the uncertainties and heterogeneities in rail deterioration processes;

Table 7. Rail design working life of the Beijing Metro

\begin{tabular}{|c|c|c|c|}
\hline No. & $\begin{array}{c}\text { Type of rail } \\
{[\mathrm{kg} / \mathrm{m}]}\end{array}$ & $\begin{array}{c}\text { Type of } \\
\text { track }\end{array}$ & $\begin{array}{c}\text { Accumulated gross tonnage } \\
{[\text { Million Gross Tonnes (MGT) }]}\end{array}$ \\
\hline 1 & 60 & jointless & 600 \\
\hline 2 & 60 & jointed & 500 \\
\hline 3 & 50 & jointless & 450 \\
\hline 4 & 50 & jointed & 400 \\
\hline 5 & 43 & jointed & 150 \\
\hline
\end{tabular}

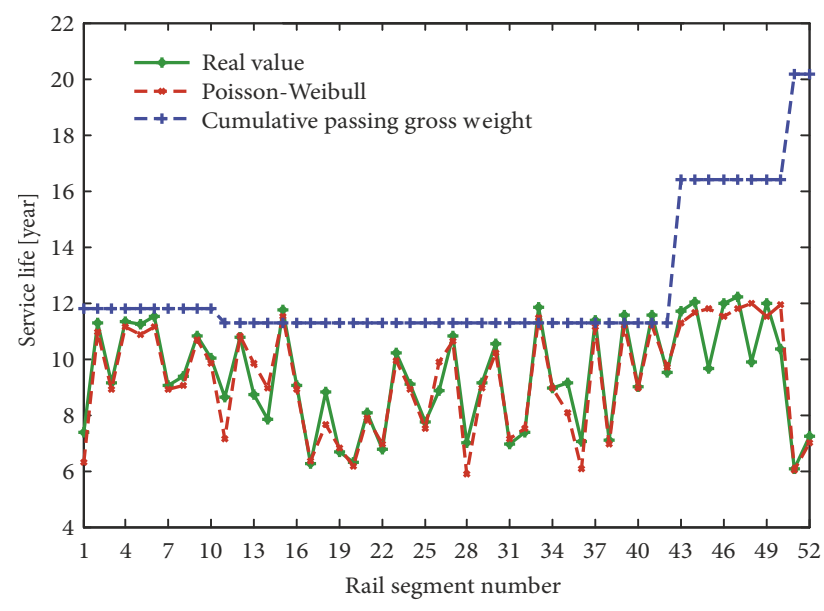

Figure 7. Comparison between service lives of selected rail segments across methods
- the differences between the results calculated using the proposed method and the actual results for most of the rail segments examined in this study are smaller than those between the results calculated using the accumulated gross tonnage and actual results; this indicates that the proposed method is more effective than the accumulated gross tonnage method;

- the results calculated using the proposed method and the actual results for most of the rail segments are lower than the results calculated using the accumulated gross tonnage; this is because the selected rail segments in which severe or broken rail defects occurred more than three times are mostly located on sharp curves and their deterioration rates are faster under the influence of rail wear.

Consequently, managing rail renewal based on accumulated gross tonnage may lead to over-extended service of rails.

\subsection{Discussion}

In summary, the main advantages of the proposed model include the customized degradation rules and service life estimation model for each asset, considering the uncertainty and heterogeneity in deterioration. In addition, the estimated service life values of the various assets are more accurate, and the renewal demand and renewal period of each asset can be analysed quantitatively. Moreover, compared with the existing renewal method, the proposed method is more feasible and has higher efficiency. However, the application of the proposed method relies on detailed inspection and maintenance records for each asset. Based on the continued accumulation of these data, the estimation accuracy can be further improved.

\section{Conclusions}

Decision-making surrounding asset renewal is essential for the efficient use of renewal resources and the safe operation of urban rail transit. In this paper, the authors first analysed the asset renewal management methods for urban rail transit asset in countries with the same problems as China, that is, design working life and health condition are the major two bases of managing asset renewal. The main problems in the existing management methods were then summarized; these include the insufficient consideration of the uncertainty and heterogeneity in asset deterioration in the existing design-working-life-based renewal method and low efficiency and poor manoeuvrability of expert evaluation in the existing health-condition-based renewal method.

Secondly, in response to the existing problems, a renewal management framework based on the service life estimation was proposed to provide decision-making support for urban rail transit assets. In this framework, the cumulative failure frequency of an asset serves as its health condition indicator, and a Poisson-Weibull process model-based methodology was developed to estimate the ser- 
vice and residual lives of each asset to analyse its renewal demand and renewal period quantitatively, considering the uncertainty and heterogeneity in the deterioration.

Finally, an empirical study of rail renewal was conducted in Beijing Metro to verify the effectiveness of the proposed method. In this case, continuous railway lines were divided into adjacent $1-\mathrm{km}$ segments based on the actual management demand, and the service and residual lives of each rail segment were calculated using the proposed method based on historical rail inspection data from January 2008 to March 2017. Furthermore, the estimated values were compared with the actual values, and the estimation errors were analysed. The results demonstrated that the accuracy of the proposed model would allow management personnel to compose a reasonable renewal plan, providing a sufficient accurate estimation of the service life to support renewal decisions and a quantifiable, scientific basis for the allocation of resources. Further, a comparison was drawn between the estimated values obtained using the proposed method and accumulated gross tonnage, indicating that the proposed method avoids the main problems arising in the existing management methods, is more feasible, and has higher efficiency.

However, the application of the proposed method relies on detailed inspection and maintenance records for each asset. Based on the continued accumulation of these data, the estimation accuracy can be further improved. Several points that were not discussed in the current study may serve as topics for extending this study in the future:

- with so many kinds of urban rail transit assets, the threshold of the health condition indicator presented in this paper for each kind should be studied;

- the effects of heterogeneous factors on the deterioration processes of different assets, such as design factors and natural factors, should be examined.

\section{Funding}

This work was supported by the National Natural Science Foundation of China under Grant No 51578057 and No 71801010, and the State Key Laboratory of Rail Traffic Control and Safety of Beijing Jiaotong University (China) under Grant No RCS2016ZT007.

\section{Disclosure statement}

The authors declare that there are no conflicts of interest.

\section{References}

Andrade, A. R.; Teixeira, P. F. 2013. Hierarchical Bayesian modelling of rail track geometry degradation, Proceedings of the Institution of Mechanical Engineers, Part F: Journal of Rail and Rapid Transit 227(4): 364-375.

https://doi.org/10.1177/0954409713486619

Aoki, K.; Yamamoto, K.; Kobayashi, K. 2007. Optimal inspection and replacement policy using stochastic method for deterioration prediction, in The 11th World Conference on Transportation Research, 24-28 June 2007, Berkeley CA, US, 1-13.
Bai, L.; Liu, R.; Sun, Q.; Wang F.; Xu, P. 2015. Markov-based model for the prediction of railway track irregularities, Proceedings of the Institution of Mechanical Engineers, Part F: Journal of Rail and Rapid Transit 229(2): 150-159. https://doi.org/10.1177/0954409713503460

Baik, H.-S.; Jeong, H. S.; Abraham, D. M. 2006. Estimating transition probabilities in Markov chain-based deterioration models for management of wastewater systems, Journal of Water Resources Planning and Management 132(1): 15-24. https://doi.org/10.1061/(ASCE)0733-9496(2006)132:1(15)

Barone, G.; Frangopol, D. M. 2014. Life-cycle maintenance of deteriorating structures by multi-objective optimization involving reliability, risk, availability, hazard and cost, Structural Safety 48: 40-50.

https://doi.org/10.1016/j.strusafe.2014.02.002

Caetano, L. F.; Teixeira, P. F. 2013. Availability approach to optimizing railway track renewal operations, Journal of Transportation Engineering 139(9): 941-948.

https://doi.org/10.1061/(ASCE)TE.1943-5436.0000575

Caetano, L. F.; Teixeira, P. F. 2016. Predictive maintenance model for ballast tamping, Journal of Transportation Engineering 142(4): 04016006.

https://doi.org/10.1061/(ASCE)TE.1943-5436.0000825

Cao, J. H.; Cheng, K. Z. 2012. Introduction to Reliability Mathematics. Beijing: Higher Education Press. (in Chinese).

Chen, L.; Ng, J. 2007. Asset management for urban rail transit, Urban Rapid Rail Transit 20(4): 21-24 (in Chinese). https://doi.org/10.3969/j.issn.1672-6073.2007.04.007

CAM. 2017. Annual statistics and analysis report of urban rail transit. Report. China Association of Metros (CAM). (in Chinese).

DB 11/995:2013. Code for Design of Urban Rail Transit. Chinese Standard (in Chinese).

DB 11/T718:2016. Code for Maintenance of Urban Rail Transit Facility. Chinese Standard (in Chinese).

Durango-Cohen, P. L.; Madanat, S. M. 2002. Optimal maintenance and repair policies in infrastructure management under uncertain facility deterioration rates: an adaptive control approach, Transportation Research Part A: Policy and Practice 36(9): 763-778.

https://doi.org/10.1016/S0965-8564(01)00038-6

Durango-Cohen, P. L.; Madanat, S. M. 2008. Optimization of inspection and maintenance decisions for infrastructure facilities under performance model uncertainty: a quasi-Bayes approach, Transportation Research Part A: Policy and Practice 42(8): 1074-1085. https://doi.org/10.1016/j.tra.2008.03.004

GB 50157:2013. Code for Design of Metro. Chinese Standard (in Chinese).

GB 50490:2009. Technical Code of Urban Rail Transit. Chinese Standard (in Chinese).

Han, D.; Kaito, K.; Kobayashi, K. 2014. Application of Bayesian estimation method with Markov hazard model to improve deterioration forecasts for infrastructure asset management, KSCE Journal of Civil Engineering 18(7): 2107-2119. https://doi.org/10.1007/s12205-012-0070-6

Hegazy, T.; Rashedi, R. 2013. Large-scale asset renewal optimization using genetic algorithms plus segmentation, Journal of Computing in Civil Engineering 27(4): 419-426. https://doi.org/10.1061/(ASCE)CP.1943-5487.0000249

IEC 62278:2002. Railway Applications. Specification and Demonstration of Reliability, Availability, Maintainability and Safety (RAMS).

ISO 2394:2015. General Principles on Reliability for Structures. Kobayashi, K.; Kaito, K.; Lethanh, N. 2010. Deterioration fore- 
casting model with multistage weibull hazard functions, Journal of Infrastructure Systems 16(4): 282-291.

https://doi.org/10.1061/(ASCE)IS.1943-555X.0000033

Kobayashi, K.; Kaito, K.; Lethanh, N. 2012. A statistical deterioration forecasting method using hidden Markov model for infrastructure management, Transportation Research Part B: Methodological 46(4): 544-561.

https://doi.org/10.1016/j.trb.2011.11.008

Li, Y.-L.; Wang, Y. 2012. Problems and recommendations of Beijing metro asset management, Journal of Transportation Systems Engineering and Information Technology 12(2): 194-197. (in Chinese).

https://doi.org/10.16097/j.cnki.1009-6744.2012.02.008

Liu, Z. L.; Bai, Y.; Wu, Y. L. 2011. Decision-making method on rail transit infrastructure renovation project, International Conference on Management Science and Engineering, Advances in Artificial Intelligence, 1 January 2011, Chengdu, China, 351-356.

Mishalani, R. G.; Gong, L. 2009. Optimal infrastructure condition sampling over space and time for maintenance decisionmaking under uncertainty, Transportation Research Part B: Methodological 43(3): 311-324.

https://doi.org/10.1016/j.trb.2008.07.003

Mishalani, R. G.; Madanat, S. M. 2002. Computation of infrastructure transition probabilities using stochastic duration models, Journal of Infrastructure Systems 4(8): 139-148. https://doi.org/10.1061/(ASCE)1076-0342(2002)8:4(139)

QB(J)/BDY(A)XL 003:2009. Beijing Metro Track Maintenance Rules (in Chinese).

Rashedi, R.; Hegazy, T. 2016. Holistic analysis of infrastructure deterioration and rehabilitation using system dynamics, Journal of Infrastructure Systems 22(1): 04015016. https://doi.org/10.1061/(ASCE)IS.1943-555X.0000273

Rashedi, R.; Hegazy, T. 2015. Capital renewal optimisation for large-scale infrastructure networks: genetic algorithms versus advanced mathematical tools, Structure and Infrastructure Engineering: Maintenance, Management, Life-Cycle Design and Performance 11(3): 253-262.

https://doi.org/10.1080/15732479.2013.866968

Scarf, P.; Dwight, R.; McCusker, A.; Chan, A. 2007. Asset replacement for an urban railway using a modified two-cycle replacement model, Journal of the Operational Research Society 58(9): 1123-1137.

https://doi.org/10.1057/palgrave.jors.2602288

Scarf, P. A.; Hartman, J. C. 2008. Replacement of capital equipment, in K. A. H. Kobbacy, D. N. P. Murthy (Eds.). Complex System Maintenance Handbook, 287-319.

https://doi.org/10.1007/978-1-84800-011-7_12

The Railway Ministry of People's Republic of China. 2010. Rules of Railway Track Maintenance. 1st edition. Beijing: China Railway Publishing House (in Chinese).

Zakeri, J.-A.; Shahriari, S. 2012. Developing a deterioration probabilistic model for rail wear, International Journal of Traffic and Transportation Engineering 1(2): 13-18.

Zambon, I.; Vidovic, A.; Strauss, A.; Matos, J.; Amado, J. 2017. Comparison of stochastic prediction models based on visual inspections of bridge decks, Journal of Civil Engineering and Management 23(5): 553-561. https://doi.org/10.3846/13923730.2017.1323795

Zhang, J. X.; Han, B. M. 2011. Research on management modes of Beijing urban rail transit asset replacement and renovation, International Conference on Information, Services and Management Engineering, 26-28 December 2011, Beijing, China, 2029-2031. 